\title{
A FÁBRICA MÍNIMA: tecnologias digitais para a produção local e customizada de artefatos físicos
}

\author{
Alexandre Monteiro de Barros \\ Universidade Federal do Rio Grande do Sul \\ alembarros@gmail.com \\ Natalia Schmitt Silveira \\ Universidade Federal do Rio Grande do Sul \\ natisilveira@gmail.com
}

\begin{abstract}
Resumo: Este artigo aborda a aplicação das tecnologias de fabricação digital para uma produção local, customizada e sob demanda de artefatos físicos, em contraste com a atual produção global e em série contemporânea, especificamente mobiliário, luminárias e utensílios domésticos. Esta aplicação define um novo modelo de produção que implica em novas formas de projetar, produzir e comercializar os artefatos e pode contribuir significativamente com a sustentabilidade ambiental no design de produto. É apresentado o desenvolvimento e a aplicação real de um modelo de produção estruturado com as características acima mencionadas, permitindo descrever aspectos relevantes e indicar futuras questões a serem investigadas e aperfeiçoadas.
\end{abstract}

Palavras-chave: design de produto, fabricação digital, design sustentável, ecodesign, artefatos físicos 


\section{INTRODUÇÃO}

Através das tecnologias de fabricação digital, o modelo de produção tradicional, baseado na manufatura em série, na economia de escala e na localização globalizada pode ser complementado ou parcialmente substituído por novos modelos que sejam mais eficientes em relação ao meio ambiente e a sociedade sob determinados aspectos. Conforme Gershenfeld (2012), as tecnologias de fabricação digital envolvem a habilidade de transformar dados em "coisas" e "coisas" em dados. Pesquisas de ponta estão explorando a aplicação das tecnologias de fabricação digital para os mais diversos fins e em diferentes escalas, desde nano até macros componentes com possibilidades de auto-replicação, montagem auto-suficiente e comunicação integrada (GERSHENFELD, 2012). Em paralelo, as tecnologias já consolidadas vêm se tornando mais acessíveis para médios e pequenos produtores, para grupos de pesquisas acadêmicos e, em alguns casos, para consumidores em geral, permitindo investigar sua aplicação em novos modelos de produção de artefatos físicos.

Com relação aos aspectos de sustentabilidade ambiental, as tecnologias de fabricação digital apresentam vantagens para a confecção de determinados artefatos quando comparadas aos processos tradicionais de manufatura. Os equipamentos de manufatura podem ser leves, padronizados e altamente flexíveis, em contraste com equipamentos pesados, diversificados e de difícil reconfiguração (DEMAT, 2013). Em muitos casos há um menor consumo de energia, uma redução no numero de equipamentos e no projeto é possível aplicar lógicas de montagem e desmontagem mais eficientes e adaptáveis (GONDIM, 2010). Constata-se uma crescente oferta de materiais para as tecnologias de fabricação digital que são provenientes de fontes renováveis ou com baixa emissão de resíduos para seu processamento, como os biopolímeros e os materiais naturais.

Embora pesquisas sobre novos modelos de produção utilizando os recursos de fabricação digital já datem de mais de uma década (STEFFEN \& GROS, 2003), sua real aplicação ainda é limitada e pouco difundida. Um fator para este cenário pode ser a dificuldade de estabelecer os padrões de fabricação, como por exemplo, uma base de materiais genéricos com propriedades idênticas ou facilmente adaptáveis para diferentes regiões geográficas. Outros fatores podem estar relacionados com a viabilidade econômica, o desconhecimento por parte dos consumidores ou ainda a compreensão destas tecnologias por parte de designers e pequenos produtores, o que faz necessário comunicar, refletir e propor novos enfoques sobre as mesmas. Este artigo reúne uma fundamentação teórica sobre novos modelos de produção relacionados com as tecnologias digitais e apresenta a aplicação de um modelo específico que utiliza estas tecnologias para produzir e comercializar mobiliário e equipamentos complementares através de uma rede colaborativa de designers independentes associados a uma empresa privada. Através da aplicação deste modelo, foi possível levantar um conjunto de questões para discussão e investigação. Esperase que a partir deste trabalho outras iniciativas como esta possam ser replicadas, ampliadas e aperfeiçoadas, rumo a uma produção e consumo mais sustentável em relação ao meio ambiente e a sociedade como um todo. 


\section{MODELOS DE PRODUÇÃO}

Observa-se que no panorama global da produção de mobiliário, a organização industrial é caracterizada pela presença de grandes empresas especializadas em linhas específicas de produtos, dedicando-se a produzir commodities, ou seja, produtos padronizados baseados no preço. Embora as tecnologias computacionais contribuam para o aumento do nível de produtividade nas indústrias, estas tecnologias não são totalmente exploradas, pois a flexibilidade na linha de produção ainda é limitada pela organização industrial vigente. A produção em larga escala permite atingir um alto nível de qualidade e uma considerável redução nos custos dos produtos, mas por outro lado este tipo de produção está associado a uma fabricação padronizada e pouco flexível, ao contrário da produção artesanal, onde é possível concentrar esforços em séries menores ou produtos únicos com alto grau de customização.

A produção artesanal do mobiliário diminuiu gradualmente de escala e importância ao longo do século XX, pois pequenas empresas não se encontravam aptas para competir com grandes indústrias que são baseadas na economia de escala e no custo da produção (STEFFEN e GROS, 2003). Entretanto, Mitchell e Watt (2009) sugerem que a produção em massa e as grandes fábricas vão perder importância frente a novos modelos de produção que retomem os padrões de fabricação do passado, ou seja, em menor escala e adaptado as necessidades individuais dos consumidores. Isto decorre das deficiências apresentadas pelos modelos de produção em escala industrial. As fábricas são orientadas para produzir grandes quantidades de um mesmo tipo de produto, não lidando bem com pequenas quantidades de forma eficiente, apresentando pouca flexibilidade. Ademais, este modelo de produção gera uma enorme quantidade de estoque, pois não atende uma demanda individual ou de pequenos lotes, e necessita de amplo espaço para armazenar, distribuir e comercializar seus produtos.

Outra importante questão é a localização deste modelo de indústria, que migrou seu capital para regiões que apresentavam menores custos de mão de obra e insumos, não importando a proximidade com o mercado consumidor, pois o alto volume de produção viabiliza o transporte das mercadorias sem agregar um custo que vá prejudicar sua competitividade, mas quando confrontada a fornecer produtos customizados esbarra no fator tempo e custo de transporte (MITCHELL e WATT, 2009). Raymond (2009) observa dois tipos de fábricas de mobiliário capazes de prosperar no futuro considerando a produção doméstica dos produtos. Ambas devem seguir um sólido plano de negócios, com ênfase nos consumidores. Embora um modelo seja baseado na alta produtividade, com baixo custo de produção e poucas variedades de produtos, contrastando com a opinião de Mitchell e Watt (2009), o outro modelo são as fábricas de médio porte, com produtos altamente customizáveis e uma linha de produção flexível, modelo em consenso com Steffen e Gros (2003) e Mitchell e Watt (2009). O principal recurso para este modelo de produção são os sistemas de informação aplicados no projeto e na produção dos produtos. 
A incorporação da informação de maneira automatizada nos processos de produção é um dos principais fatores que permite propor novas lógicas para produção do mobiliário e ao mesmo tempo expandir a capacidade de atuação das fábricas para outros segmentos. Neste contexto, é possível agrupar um conjunto de atributos genéricos para o modelo de produção do mobiliário e organizá-los com relação a períodos temporais básicos, conforme colocado no quadro 1. No capítulo seguinte se abordam questões relacionadas com as tecnologias digitais que são importantes para a compreensão e aplicação dos novos modelos de produção.

\section{Quadro 1 - Atributos das fábricas}

\begin{tabular}{|c|c|c|c|}
\hline Atributo & Passado & Presente & $\begin{array}{c}\text { Alternativa para o } \\
\text { Futuro }\end{array}$ \\
\hline Tamanho da fábrica & $\begin{array}{c}\text { Micro e pequenas } \\
\text { empresas } \\
\text { (1 a } 20 \text { funcionários) }\end{array}$ & $\begin{array}{l}\text { Médias e grandes } \\
\text { (50 até mais de } 500 \\
\text { funcionários) }\end{array}$ & $\begin{array}{c}\text { Micro, pequenas e } \\
\text { médias } \\
\text { (1 até } 200 \text { funcionários) }\end{array}$ \\
\hline Volume de Produção & $\begin{array}{l}\text { Baixo } \\
\text { (produção sob } \\
\text { encomenda) }\end{array}$ & $\begin{array}{c}\text { Alto } \\
\text { (produção em massa) }\end{array}$ & $\begin{array}{c}\text { Baixo ou Médio } \\
\text { (produção sob encomenda } \\
\text { ou séries limitadas) }\end{array}$ \\
\hline Mercado consumidor & Local & Regional e Global & Local e Regional \\
\hline $\begin{array}{l}\text { Projeto do produto } \\
\text { em relação ao } \\
\text { consumidor }\end{array}$ & Customizado & Seriado & Customizado \\
\hline $\begin{array}{l}\text { Flexibilidade da linha } \\
\text { de produção }\end{array}$ & Média & Muito baixa & Alta \\
\hline $\begin{array}{l}\text { Integração entre } \\
\text { projeto e produção }\end{array}$ & $\begin{array}{c}\text { Sem integração } \\
\text { (desenhos bidimensionais) }\end{array}$ & $\begin{array}{l}\text { Limitada } \\
\text { (controle de processos } \\
\text { específicos) }\end{array}$ & $\begin{array}{c}\text { Alta } \\
\text { (diferentes processos } \\
\text { em um mesmo } \\
\text { equipamento) }\end{array}$ \\
\hline Matéria-prima & Madeira sólida & $\begin{array}{c}\text { Compósito de } \\
\text { madeira e resina } \\
\text { Metal }\end{array}$ & $\begin{array}{c}\text { Madeira sólida } \\
\text { Compósito de madeira } \\
\text { e resina } \\
\text { Polímero }\end{array}$ \\
\hline $\begin{array}{l}\text { Manipulação da } \\
\text { matéria-prima }\end{array}$ & Manual & $\begin{array}{c}\text { Mecânica } \\
\text { (controle manual e } \\
\text { controle } \\
\text { computacional) }\end{array}$ & $\begin{array}{c}\text { Mecânica } \\
\text { (controle } \\
\text { computacional) }\end{array}$ \\
\hline
\end{tabular}

Fonte: Elaborado pelos autores, com base na pesquisa realizada 


\section{TECNOLOGIAS DIGITAIS}

Conforme Schindler (2007) o processo para a produção de artefatos físicos envolve três parâmetros essenciais: (I) informação, (II) energia e (III) material, e é possível verificar três ondas na forma de combiná-los ao longo da história da humanidade, cada uma definindo um conjunto de tecnologias específicas. A primeira onda define a tecnologia de ferramenta manual, a segunda define a tecnologia de ferramenta máquina e a terceira define a tecnologia de ferramenta informacional. Estas ondas não delimitam períodos específicos, mas sobrepõem-se no decorrer do desenvolvimento dos processos de produção. A tecnologia de ferramenta manual é caracterizada pelo uso da energia, do material e do processamento da informação por um operador humano. A tecnologia de ferramenta máquina é o uso da energia e do processamento de material por uma máquina que substituí operações físicas repetitivas enquanto é controlada por um operador humano. A tecnologia de ferramenta informacional é o uso de energia, de material e o processamento da informação por uma máquina para substituir operações humanas físicas e intelectuais (SCHINDLER, 2007). A fabricação digital engloba a produção de artefatos físicos através de modelos computacionais e está associada com a tecnologia de ferramenta informacional para materialização dos artefatos.

As novas tecnologias computacionais podem ser aplicadas nos processos de projeto e de produção para equilibrar o descompasso existente entre a produção artesanal e a produção industrial de mobiliário. Conforme Steffen e Gros (2003), com centros de usinagem por controle numérico computadorizado e cortadoras laser, as pequenas e médias empresas estão habilitadas a utilizar as mesmas ferramentas tecnológicas das grandes indústrias. Do mesmo modo, a lógica da produção industrial pode ser ajustada para atender uma demanda cada vez mais específica e variável. A figura 1 classifica diferentes sistemas de manufatura em relação aos atributos de produtividade e flexibilidade, onde se observa que os sistemas com equipamentos controlados numericamente são altamente flexíveis, mas com pouca ou razoável produtividade.

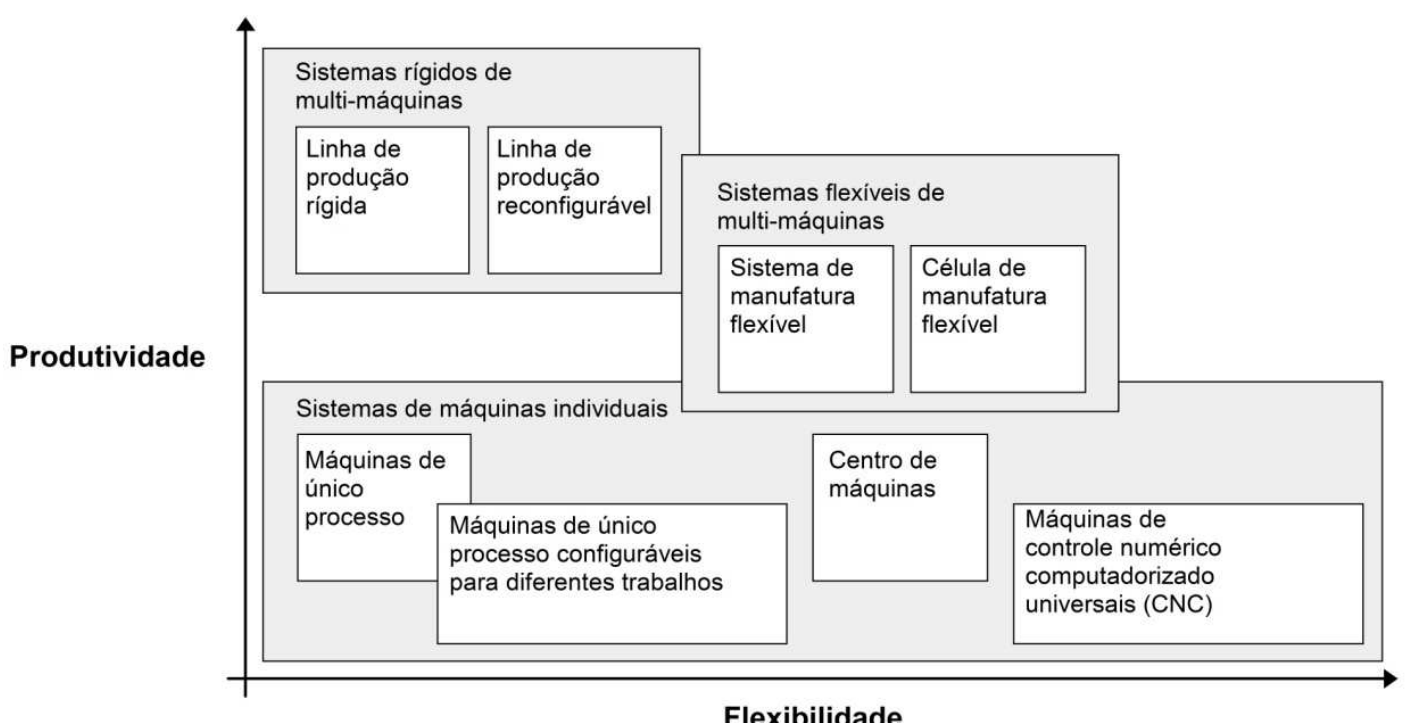

Flexibilidade

Figura 1 - Relações gerais entre sistemas de manufatura Fonte: Adaptado de Schodek (2005). 
As máquinas universais de CNC se enquadram em três sistemas distintos de fabricação: os sistemas subtrativos, envolvendo o corte e a usinagem dos materiais, os sistemas aditivos, envolvendo a deposição e solidificação de material em camadas e os sistemas formativos, baseado em moldes dinâmicos e menos difundido que os sistemas anteriores. Conforme Sass, Michaud e Cardoso (2007), a materialização dos artefatos através de sistemas subtrativos com máquinas por controle numérico computadorizado é feita em quatro passos, que se iniciam com um (I) modelo tridimensional que é traduzido para (II) um conjunto de componentes que são posicionados (III) em forma bidimensional para a produção (CNC) e, posteriormente, (IV) montado à mão.

Steffen e Gros (2003) estruturaram um novo modelo de produção orientado para a produção flexível, sob demanda e customizada utilizando as tecnologias digitais. Estes autores propõem um cenário de produção virtual onde os produtos sejam formulados e resultem num conjunto de dados virtuais aptos para a materialização através de máquinas de CNC. Os Editores de produto são responsáveis por operar um diretório e comercializar os produtos. $\mathrm{O}$ co-desinger integra compradores e projetistas para gerar o mobiliário customizado. Galeria de produto expõe exemplos materiais de mobiliário e constitui a interface física entre comprador e produtor. A tecnofábrica é o local onde as máquinas de CNC manipulam a matéria-prima e materializam os artefatos, podendo estar localizadas ao lado da galeria de produto ou em outras regiões mais favoráveis (STEFFEN e GROS, 2003). A figura 2 demonstra as relações entre estes agentes e elementos, bem como suas atividades no cenário de produção virtual.

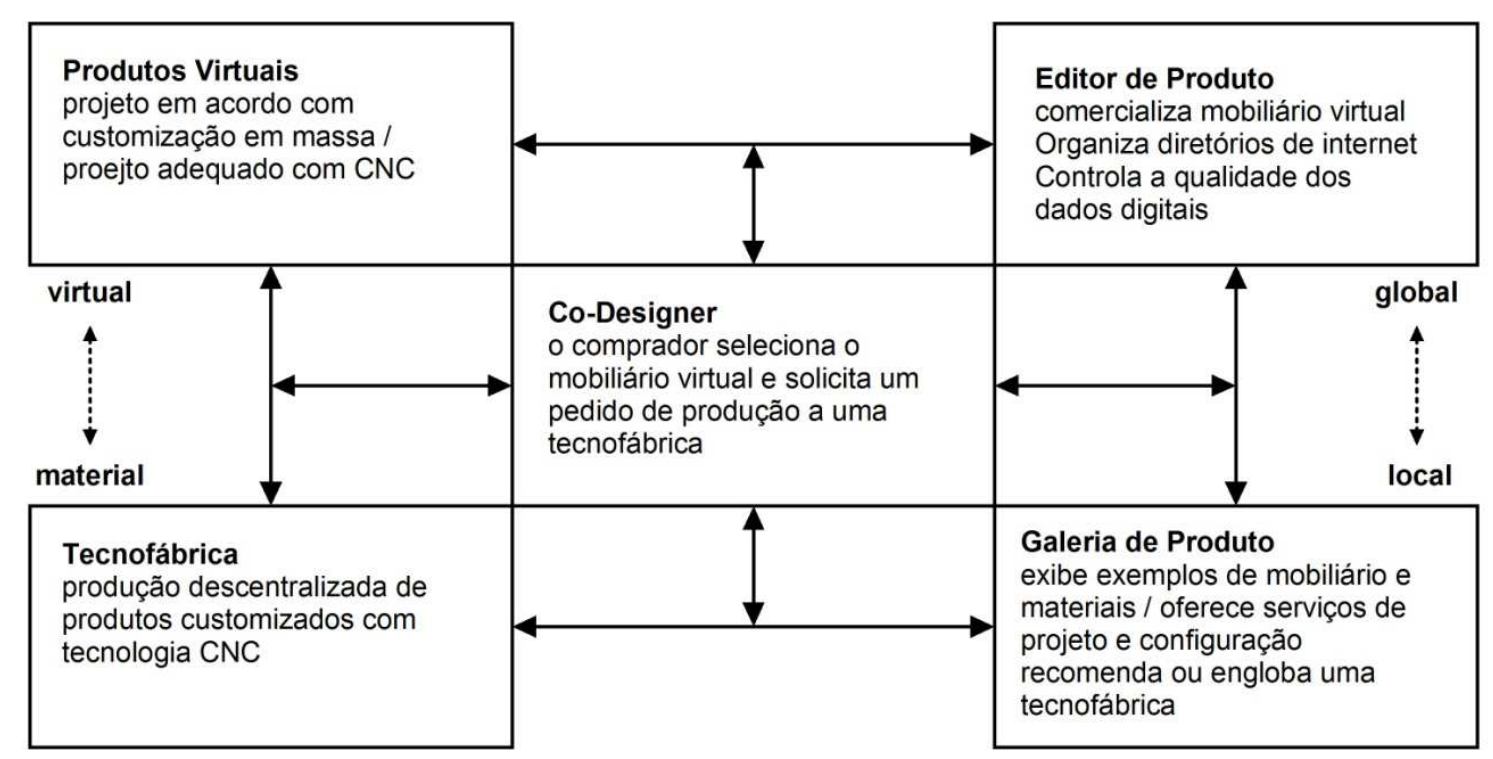

Figura 2 - Cenário da produção virtual

Fonte: Adaptado de Steffen e Gros (2003)

A seguir será apresentado o desenvolvimento e aplicação de um novo modelo de produção em acordo com a fundamentação teórica descrita acima. Esta aplicação possibilitou desenvolver uma sistematização metodológica (BARROS, 2011), a qual se pretende avançar e complementar a partir de novos trabalhos. 


\section{ESTRUTURAÇÃO E APLICAÇÃO DO MODELO DE PRODUÇÃO}

Para estruturar e aplicar um novo modelo de produção orientado para a manufatura sob demanda, flexível e customizada, os processos de projeto, de produção e de comercialização foram formatados com as características e atividades descritas a seguir como parte de um projeto paralelo de uma empresa privada que possuía os equipamentos relacionados com as tecnologias de fabricação digital. Esta experiência foi estruturada em oito meses e posteriormente aplicada por vinte e oito meses, gerando mais de 40 produtos entre mobiliários e acessórios complementares projetados por quatro grupos de designers.

\subsection{Processo de Projeto}

Inicialmente, designers foram selecionados e convidados a desenvolverem mobiliários e equipamentos complementares como luminárias e organizadores de bancada, utilizando os recursos disponíveis na empresa. Os recursos disponíveis são listados no tópico seguinte, e estão relacionados com os processos de produção. Como principal requisito de projeto, os artefatos deveriam contemplar as estratégias de sustentabilidade ambiental para o design de produto, em acordo com Manzini e Vezzoli (2009). As principais estratégias relacionavam-se com a utilização de materiais de baixo impacto ambiental, conexões facilmente reversíveis, acabamentos atóxicos e embalagens reduzidas. Para demonstrar e auxiliar o desenvolvimento dos novos produtos seguindo estes critérios foi organizado uma base de modelos precedentes conforme Barros (2011). Durante o projeto, uma extensa etapa de experimentação foi necessária até obter configurações satisfatórias dos produtos a serem produzidos. A partir das configurações selecionadas foi gerada uma base informacional com:

- Diagramas e modelos digitais do projeto de cada artefato, incluindo modelos geométricos e modelos construtivos. Em alguns casos foram desenvolvidos modelos paramétricos associados aos demais.

- Propriedades qualitativas e quantitativas organizadas em uma tabela principal com conexão para outras tabelas complementares e com o sistema de comercialização virtual.

- Imagens digitais de documentação e divulgação dos produtos. As fotos de divulgação foram produzidas em estúdio por fotógrafo profissional.

- Protótipos físicos de produção para orientar os processos de acabamento e montagem dos produtos e suas respectivas embalagens.

Determinadas propriedades desta base informacional eram diretamente conectadas com o sistema de comercialização e distribuição dos produtos descritos no item 4.3, como preço, medidas e peso, entre outras. A figura 3 contém exemplos desta base informacional, apresentado um modelo construtivo (plano de usinagem bidimensional) e imagens digitais para divulgação de um produto desenvolvido. A figura 4 ilustra um trecho da tabela com propriedades qualitativas e quantitativas. 

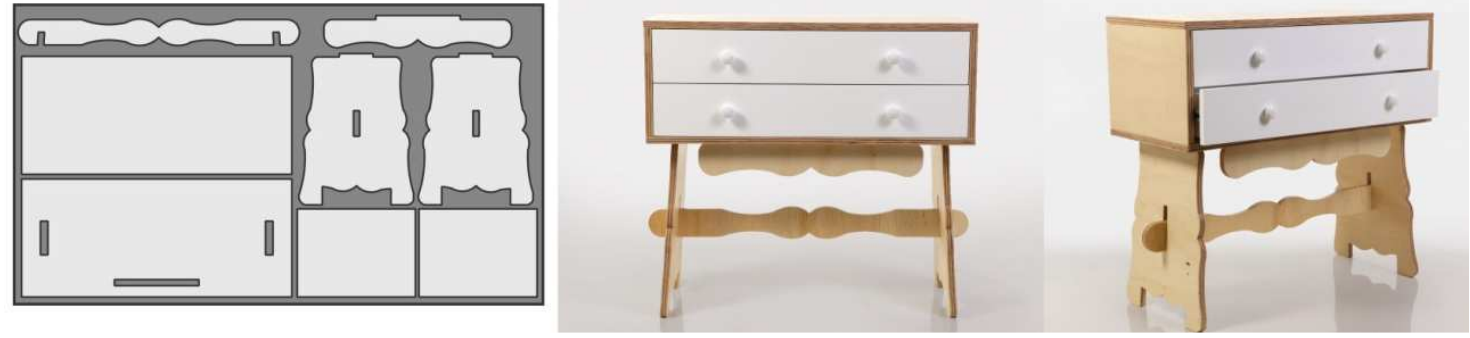

Figura 3 - Modelo construtivo e imagens de divulgação de um produto. Fonte: Elaborado pelos autores.

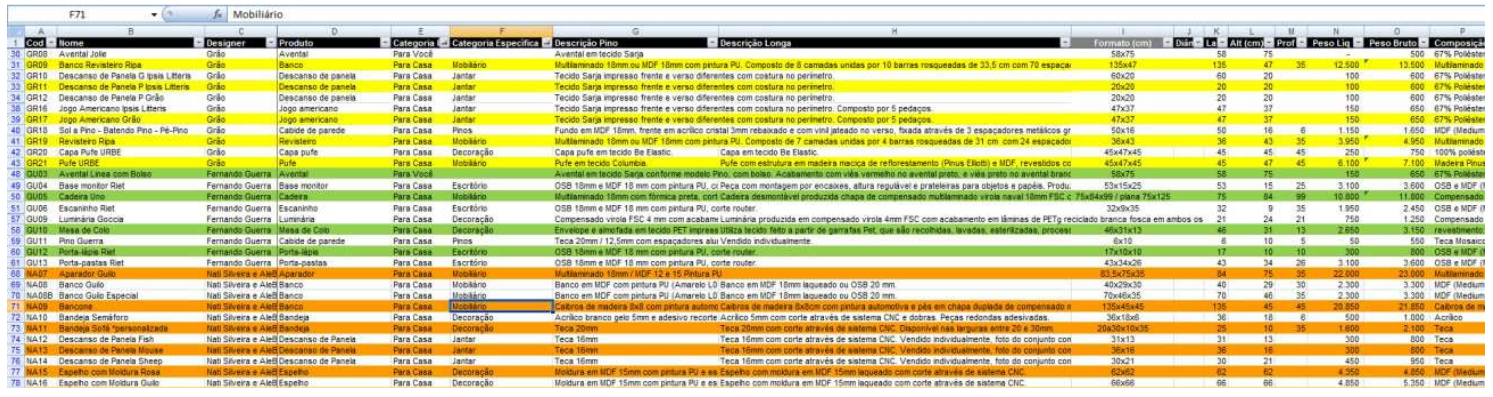

Figura 4 -Organização das propriedades qualitativas e quantitativas

Fonte: Elaborado pelos autores.

\subsection{Processos de Manufatura}

A principal tecnologia de fabricação disponível para os designers consistia em uma fresadora guiada por controle numérico computadorizado (CNC) capaz de cortar e rebaixar lâminas, chapas e placas (Figura 5). Deste modo, os arquivos digitais de projeto eram automaticamente transferidos para o equipamento de acordo com a demanda proveniente do sistema de comercialização desenvolvido. Uma base de materiais foi criada e suas principais propriedades previamente analisadas antes de serem disponibilizadas para os designers, facilitando a resolução de questões de ordem técnica. Após a usinagem dos materiais era necessário realizar processos de acabamentos e montagem, bem como preparar os produtos para a sua distribuição. Os produtos acabados eram embalados e recebiam etiquetas com seus respectivos códigos para serem encaminhados aos clientes.
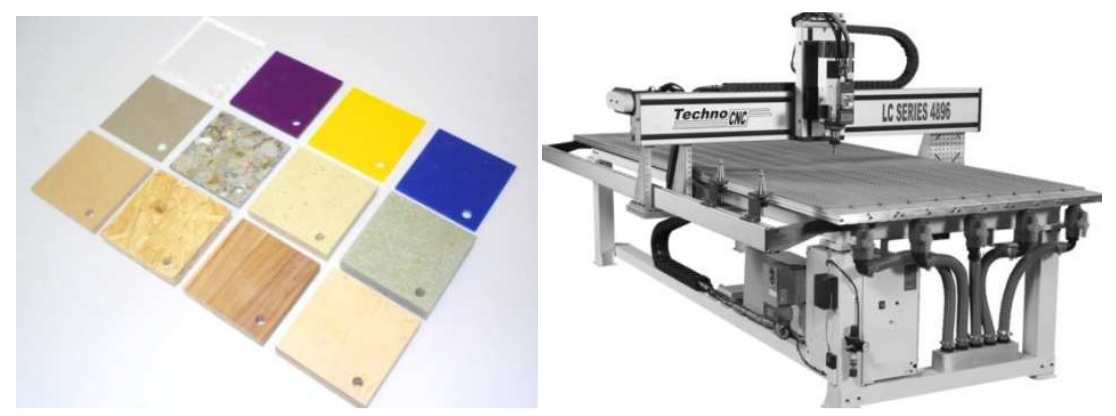

Figura 5 - Banco de materiais e Fresadora CNC

Fonte: Elaborado pelos autores. 


\subsection{Processos de Comercialização e Distribuição}

Em paralelo ao desenvolvimento inicial dos produtos pelos designers convidados, uma empresa especializada na confecção de sistemas de comercialização virtual (loja online) foi contratada para elaborar um sistema com determinadas características seguindo um modelo desenvolvido por um designer gráfico. Inicialmente, o sistema de comercialização foi elaborado para funcionar em computadores pessoais em softwares de navegação na internet, contando com um domínio próprio. O sistema contava com dois módulos principais. O primeiro módulo era de acesso restrito (interno), permitindo cadastrar e configurar uma extensa variedade de dados dos produtos, acompanhar e operar as etapas de venda e produção dos artefatos e manejar os dados dos clientes. O segundo módulo era a interface externa, ou seja, consistia no site da loja virtual onde era possível visualizar, selecionar e comprar os produtos, assim como realizar um cadastramento na modalidade cliente, efetuar pagamentos e acompanhar os pedidos efetuados.

A customização dos artefatos era restrita a parâmetros e propriedades básicas. Posteriormente, deveriam ser incluídos parâmetros avançados de customização neste sistema, entretanto a experiência foi finalizada antes desta etapa e deve ser aplicada em trabalhos futuros. Após a visualização e seleção dos produtos e suas principais características, a efetivação da aquisição mediante confirmação de pagamento gerava uma ordem de produção para a área de manufatura conforme descrito no item 4.2. A figura 4 apresenta um exemplo de tela do site.

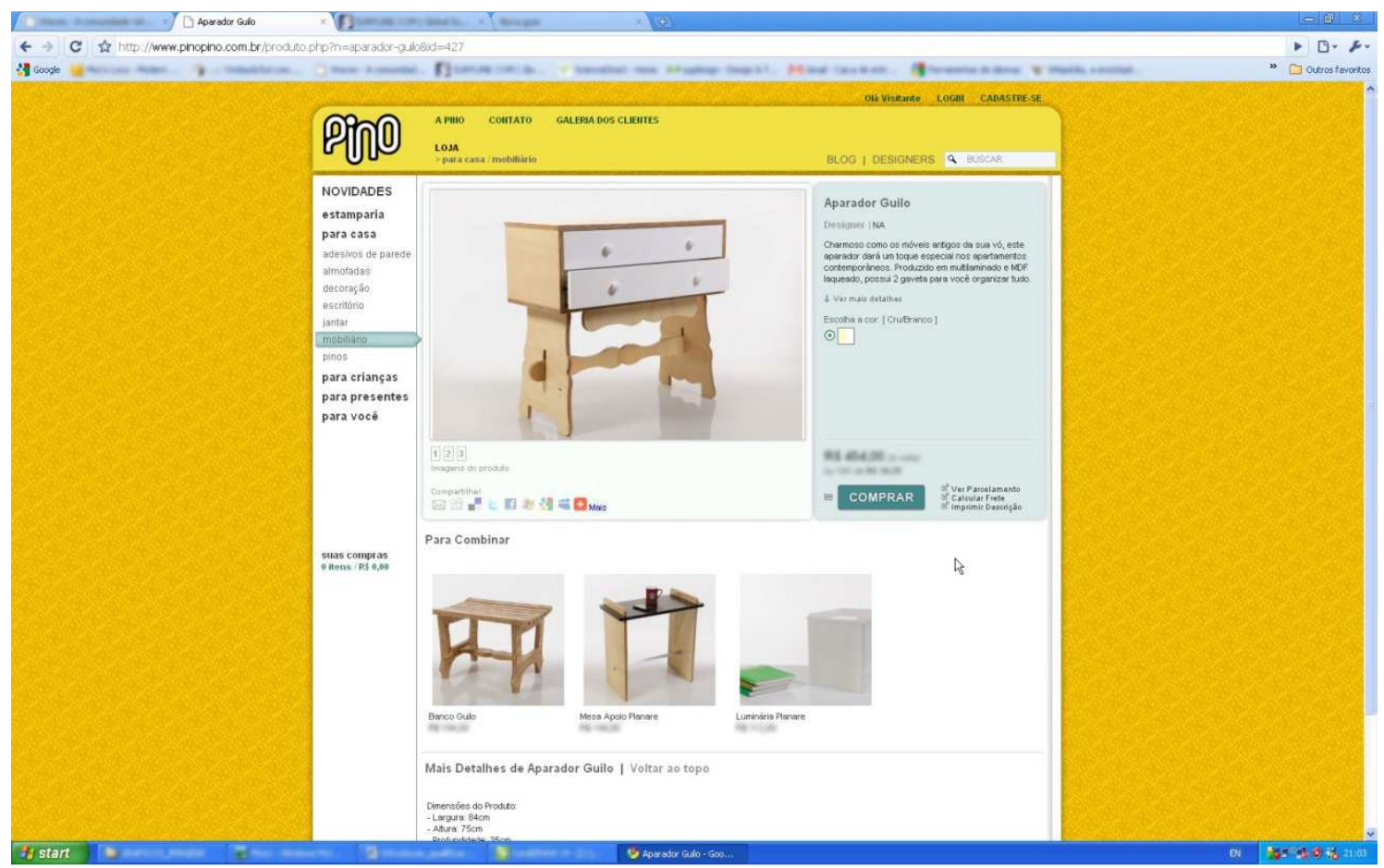

Figura 4 - Sistema de comercialização virtual desenvolvido

Fonte: Loja Pino 


\section{DISCUSSÃO}

Importantes questões foram identificadas e são discutidas a seguir. A rede colaborativa de designers compreendeu a proposta e se obteve resultados expressivos no design dos produtos elaborados. Dois produtos foram premiados em concursos de nível nacional e ademais os designers puderam incluir novos produtos nos seus portfólios, observando que cada designer desenvolveu cerca de oito produtos específicos em um curto período de tempo como uma atividade paralela.

A base informacional estruturada neste trabalho difere dos padrões tradicionais das indústrias. Normalmente, a base informacional é composta por extensos detalhamentos do produto a ser materializado que não são transferidos diretamente do projeto para a produção, necessitando de agentes intermediários que realizem tarefas manuais baseadas na interpretação e transposição da informação. No modelo apresentado, a transferência direta entre projeto e produção viabiliza o desenho de produtos mais complexos e elimina a necessidade dos agentes intermediários, facilitando a operação deste tipo de negócio. Ademais, as tecnologias digitais necessitam de indivíduos com maior grau de capacitação o que resulta em uma melhor remuneração dos agentes diretos envolvidos em todos os processos.

Embora com limitada possibilidade de customização dos artefatos, a estruturação deste novo modelo de produção deve permitir a adoção de níveis mais elaborados de customização na medida em que se avançar na integração das ferramentas utilizadas. A integração entre os parâmetros de configuração de modelos paramétricos com o sistema de comercialização pode permitir que os usuários possam alterar automaticamente algumas propriedades do produto para este ser produzido de acordo com as suas necessidades, incluindo o usuário como participante do processo de projeto. Constata-se a necessidade dos designers em captar as habilidades para manipular a matéria-prima própria dos artesões do passado e, deste modo, incorporar estratégias análogas ao projeto virtual dos artefatos. Para isso, é necessário resgatar características especiais utilizadas por eles, como as conexões baseadas em encaixes, as superfícies entalhadas, as geometrias diferenciadas e outras propriedades que são difíceis de reproduzir através do modelo de produção tradicional.

Recentemente, iniciativas que compartilham características em comum com o modelo de produção apresentado estão emergindo e se consolidando em diversos países, principalmente impulsionados pelos laboratórios de fabricação digital (fablab). Os fab labs concentram todos os recursos que estes novos modelos de produção necessitam e são pontos de experimentação que permitem desenvolver artefatos de forma livre e independente, sem necessidade de vínculo com uma empresa especifica, embora este vínculo também possa ocorrer e ser positivo para ambos os agentes, conforme constata Avogadro e Tesone (2013). Dispositivos eletrônicos de código aberto, que são facilmente configuráveis também vêm permitindo ampliar a área de experimentação das propostas existentes, especialmente com equipamentos interativos e conectados a aplicativos online. Novas pesquisas são necessárias para compreender e aprimorar cada etapa dos processos aqui apresentados. 


\section{CONCLUSÃO}

Alternativas ao modelo de produção seriada de artefatos físicos em larga escala e pouco customizáveis são possíveis de serem estruturadas e aplicadas em razão das tecnologias digitais integrarem novos modos de projetar, produzir e comercializar estes bens. A equiparação tecnológica entre pequenos e grandes produtores abre caminho para empreender em segmentos antes restritos as grandes corporações. A fábrica mínima, um modelo de produção local, baseado nas tecnologias digitais, utilizando materiais de baixo impacto ambiental e conectado a uma rede colaborativa de designers pode ser uma opção favorável em relação às questões de sustentabilidade e constitui tema relevante para futuras pesquisas e investigação no campo do design.

\section{AGRADECIMENTOS}

A CAPES (Coordenação de Aperfeiçoamento de Pessoal de Nível Superior) e a FAPERGS (Fundação de Amparo a Pesquisa do Rio Grande do Sul) pela concessão de bolsa de pesquisa. Ao professor Dr. Benamy Turkienicz.

\section{REFERÊNCIAS}

AVOGADRO, E. TESONE, J. Industrias a Medida. Revista IF. Centro Metropolitano de Diseño. Buenos Aires. 2013. n. 08. p. 32-35. Acesso em 10 de março de 2014.

Disponível em: <http://issuu.com/imdi.cmd/docs/fablab_34-37>

BARROS, A. M. de. Fabricação digital: Sistematização metodológica para o desenvolvimento de artefatos com ênfase em sustentabilidade ambiental. 2011. $102 \mathrm{f}$. Dissertação (Mestrado em Design) - Universidade Federal do Rio Grande do Sul. Escola de Engenharia. Faculdade de Arquitetura. Programa de Pós-Graduação em Design.

DEMAT. Dematerialise the Machine Tools and Manufacturing Systems. 2013

Acesso em 15 de junho de 2013. Disponível em: <http://www.dematproject.eu/index.php>

GERSHENFELD, N. How to Make Almost Anything: The Digital Fabrication Revolution. 2012. Foreign Affairs v.91. Acesso em 10 de março de 2014

Disponível em: <http://cba.mit.edu/docs/papers/12.09.FA.pdf>

GONDIM, C. Critérios para seleção de conexões em mobiliário orientado para adaptabilidade. 2010. 147 f. Dissertação (mestrado) - Universidade Federal do Rio Grande do Sul. Escola de Engenharia. Faculdade de Arquitetura. Programa de PósGraduação em Design.

HAROUNI, L. A Primer on 3D Printing. TED Talks, 2012.

Acesso em 10 de março de 2014. Disponível em:

<http://www.ted.com/talks/lisa_harouni_a_primer_on_3d_printing.html> 
MITCHELL P.; WATT H. Strategies for the New American Furniture Industry. 2009. North Carolina State University. Raleigh, North Carolina.

SASS, L.; MICHAUD, D.; CARDOSO, D. Materializing a design with plywood. In. ECAADE CONFERENCE: Predicting the future, 2007, Frankfurt. Proceedings... Frankfurt: Architecture schools at FH Wiesbaden and FH Frankfurt, 2007.

SCHINDLER, C. Information-Tool-Technology: Contemporary digital fabrication as part of a continuous development of process technology as illustrated with the example of timber construction. In. ACADIA Conference, 2007, Nova Scotia. Proceedings... Nova Scotia: Dalhousie University School of Architecture and NSCAD University, 2007.

SCHODEK, D. et. al. Digital Design and Manufacturing: CAD/CAM Applications in Architecture and Design. New Jersey: John Wiley \& Sons. 2005.

STEFFEN, D.; GROS, J. Technofactory versus Mini-Plants: Potentials for a decentralized sustainable furniture production. In. The 2nd International Conference on Mass Customization and Personalization, 2003, Munich. Proceedings... Munich: Technische Universität München (TUM).

RAYMOND A. G. Creating a Furniture Factory for the Future. 2009.

North Carolina State University. Raleigh, North Carolina.

VEZZOLI, C.; MANZINI, E. Design for Environmental Sustainability. Milão: Springer, 2010. 